\title{
Article \\ Synthesis of Induction Brazing System Control Based on Artificial Intelligence
}

\author{
Dragomir Grozdanov ${ }^{1}$, Bogdan Gilev ${ }^{2}(\mathbb{D})$ and Nikolay Hinov ${ }^{1, *}$ (I) \\ 1 Department of Power Electronics, Technical University of Sofia, 1000 Sofia, Bulgaria; \\ dragomir.grozdanov@mail.bg \\ 2 Department of Mathematical Modeling and Numerical Methods, Technical University of Sofia, \\ 1000 Sofia, Bulgaria; b_gilev@tu-sofia.bg \\ * Correspondence: hinov@tu-sofia.bg
}

Citation: Grozdanov, D.; Gilev, B.; Hinov, N. Synthesis of Induction Brazing System Control Based on Artificial Intelligence. Electronics 2021, 10, 1190. https://doi.org/10.3390/ electronics10101190

Academic Editor: Antonio Orlandi

Received: 29 April 2021

Accepted: 13 May 2021

Published: 16 May 2021

Publisher's Note: MDPI stays neutral with regard to jurisdictional claims in published maps and institutional affiliations.

Copyright: (c) 2021 by the authors. Licensee MDPI, Basel, Switzerland. This article is an open access article distributed under the terms and conditions of the Creative Commons Attribution (CC BY) license (https:// creativecommons.org/licenses/by/ $4.0 /)$.

\begin{abstract}
This paper considers the synthesis of control of an electro-technological system for induction brazing and its relationship with the guarantee of the parameters and the quality of this industrial process. Based on a created and verified 3D model of the electromagnetic system, the requirements to the system of power electronic converters for obtaining brazing between different common combinations of materials are determined. After processing and summarizing the results, an approach for automatic recognition of the type of material to be brazed is proposed and researched, as well as switching between different controller settings in order to achieve optimal performance and ease the operator. The advantages of using such an approach based on the use of artificial intelligence techniques are considered, including guidelines for its application and development in industrial systems with induction heating.
\end{abstract}

Keywords: control algorithm; artificial intelligence; induction brazing

\section{Introduction}

Induction electro-technologies are some of the most widespread in industry and household. They allow dynamic control of the transmitted power and heat output, which is one of their great advantages compared to other heating technologies [1-5]. On the other hand, due to the strong sensitivity of the parameters of the heated body from the temperature, the issues related to the optimal control of these systems are the subject of a number of studies.

Induction brazing is a process that faces a number of challenges in its realization due to its high sensitivity to the type and size of the basic materials that are brazed [6-8]. At the same time, the behavior of the various materials used in industrial production is highly dependent on their electrical and magnetic properties, which vary widely. Materials such as copper, brass, stainless steel, and aluminum have very different specific electrical resistance that in turn has different temperature dependencies. In terms of electromagnetic induction, resistance also depends on the size of the assembly being processed.

Figure 1 shows a similar comparison of resistances in three types of materials-copper, brass, and stainless steel, with the same geometry of the assembly adopted. The presented results are obtained by numerical 3D modeling discussed below.

Since the purpose of the induction system in the brazing process is to achieve a certain temperature of the assembly, it is clear that the application of a power changing over time is required according to a set dependency. This is necessary in order to achieve the repeatability of the process and to ensure quality. On the other hand, the electrical power generated in the assembly is determined by the law of Joule-Lenz, and it depends on the induced current in the assembly and the resulting electrical resistance of the area under the influence of the electromagnetic field $[2,4,9,10]$. Both values are difficult to 
define analytically, especially in a complex form of the coil, such as that of the considered induction brazing system in Figure 2.

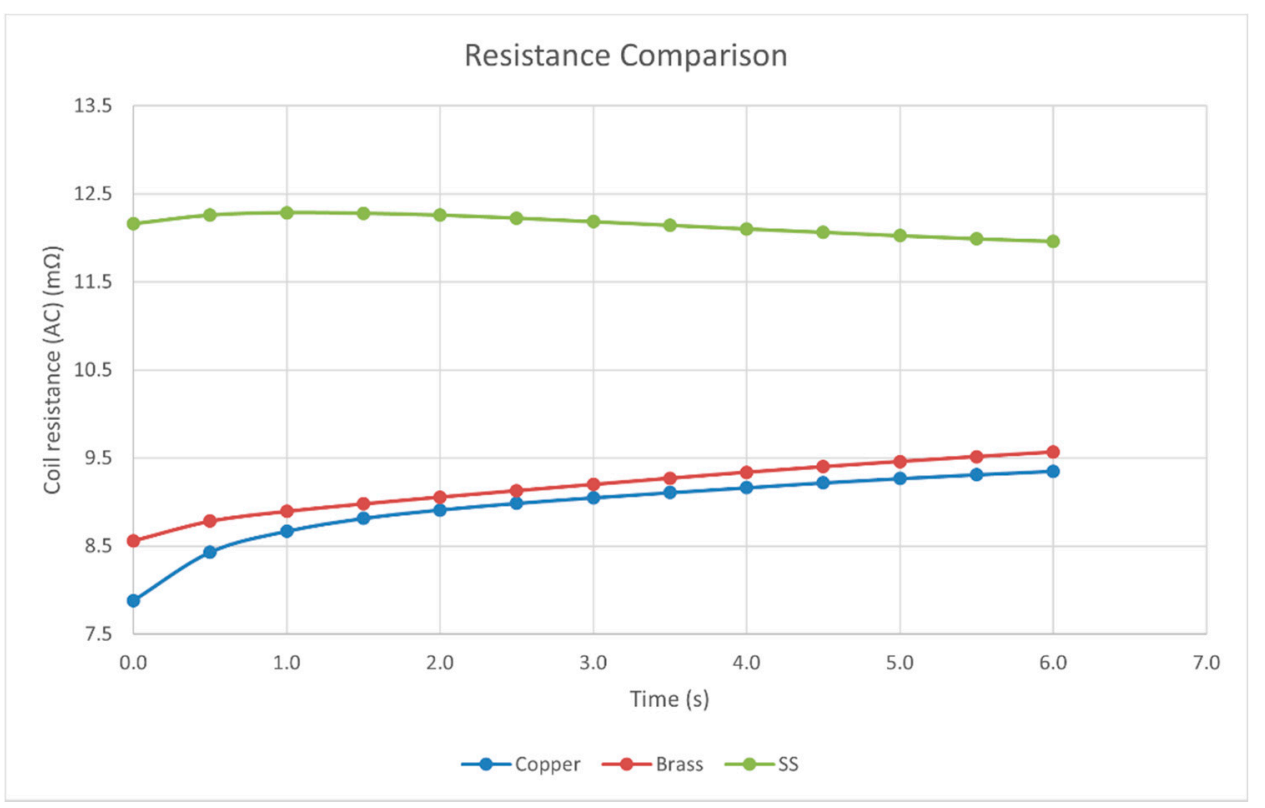

Figure 1. Transferred resistance to the inductor.

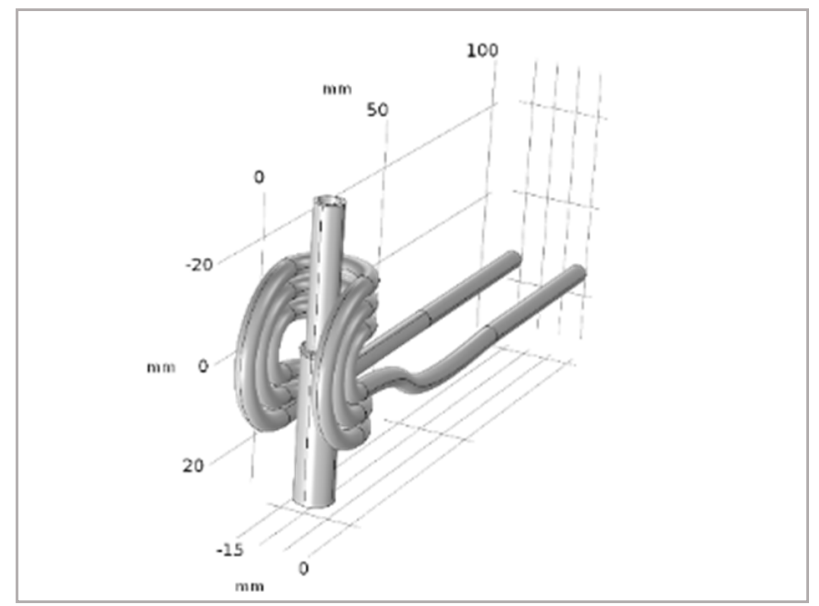

Figure 2. Induction brazing geometry.

Using COMSOL Multiphysics ${ }^{\mathrm{TM}}$ model for numerical 3D modeling of the brazing process, presented in [11] and verified by comparison with laboratory tests, the required power for brazing of the joints composed of different materials is determined. Figure 3 demonstrates the power depending on the duration of the technological process required for brazing; one of the most commonly used joints in practice is pipe-pipe, choosing three variants of the material-copper, brass, and stainless steel (the same material for both pipes). Of course, different combinations are possible depending on the specific application, which can also be evaluated using the developed model.

From the data in Figure 3, it is established that in order to perform brazing of the same size and geometry joints with the same inductor, we need to apply different power. In practice, this means that three different settings of the induction system have to be used for each of the materials. This is not a problem in nature, but it is the responsibility of the system operator to each time manually select which setting to use depending on the material to be brazed. In the case of constantly recurring operations, typical for serial production, errors are possible, leading to delay, poor results, and the need for corrections $[12,13]$. On the 
other hand, the peculiarities of these technological processes and the challenges related to ensuring the quality of products in their use in the industry are solved using artificial intelligence techniques. A complete overview of the current state of this problem in the field of power electronics is presented in [14]. The main task of this study is to present an approach based on artificial intelligence that realizes automatic material recognition and provides an appropriate setpoint to the controller and its proper processing.

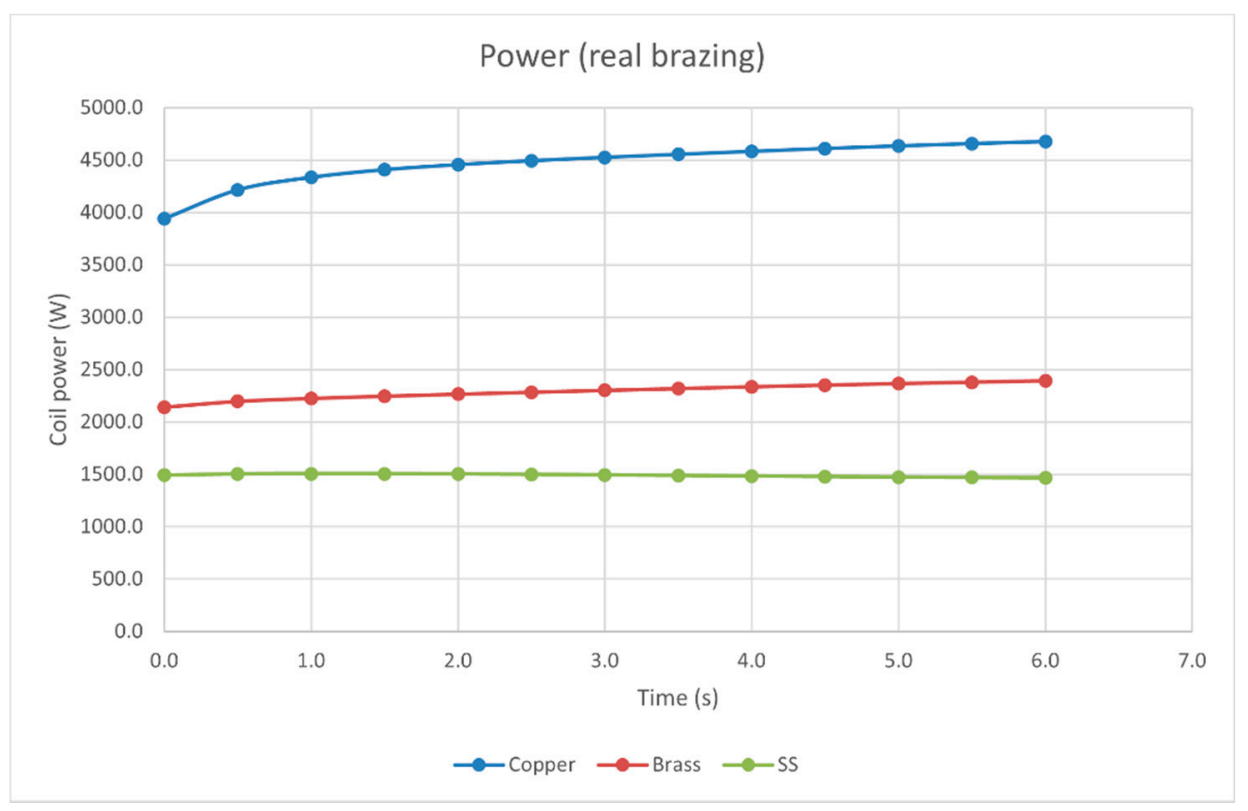

Figure 3. Brazing power.

\section{Defining the Task}

The paper proposes the use of an algorithm based on artificial intelligence techniques to remove the inconvenience of the manual adjustment of the brazing system while performing the process according to the optimal technological requirements. The proposed algorithm consists of the following three stages:

- Material recognition.

- $\quad$ Reaching the operating temperature of the process.

- Temperature retention according to technological requirements.

The block structure of an induction brazing system is shown in Figure 4. It consists of the following elements: an induction generator, matching station, brazing station, inductor, and processed assembly. A similar technological system offered on the market by UltraFlex Power Technologies [15] is shown in Figure 5. The main task in the control synthesis is focused on controlling the power supplied to the assembly that is to be brazed (workpiece). Since the components of the electronic technological system-the heating station, brazing station, and inductor-have a constant coefficient of conversion (transformation) of energy and power, there is no possibility to influence the main technological parameters through them during the process.

To achieve the optimal technological process, the main focus of the control is centered on the inverter and the ability to adjust its output power. A similar approach is presented in [16]. The control of energy flows is realized in each specific type of inverter in a different way and with different approaches, and this is not the subject of consideration in the present study. The basis of the proposed control algorithm is the use of additional feedback to give us information about the specific brazed material at the beginning of the process and the ability to automatically select the appropriate power profile in order to optimally implement the process technology. The determination of the optimal profile used in control synthesis is based on the use of numerical models of the electromagnetic system of different 
complexity and methods [17-20]. The block view of the proposed control concept is shown in Figure 6.

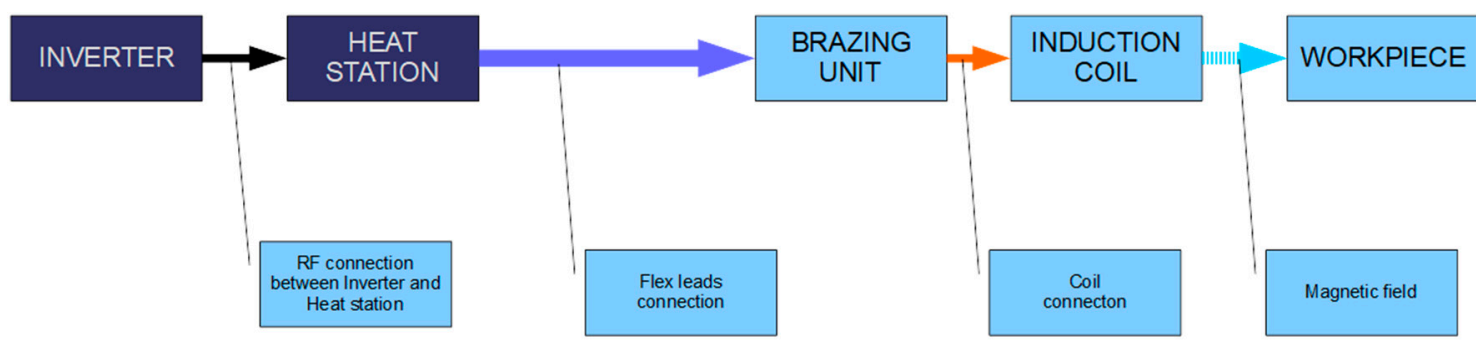

Figure 4. Block diagram of induction brazing system.

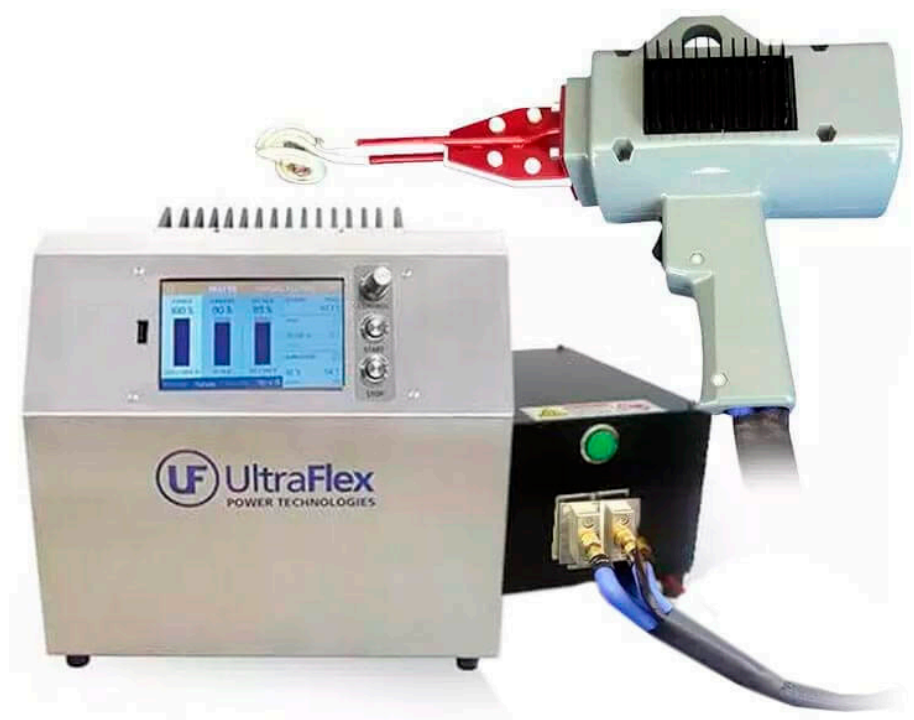

Figure 5. Induction brazing system.

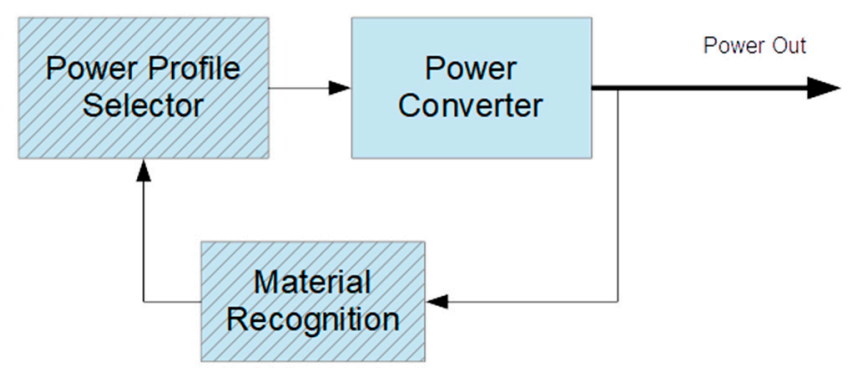

Figure 6. Block diagram of the control concept.

The specific task that is set in the synthesis of control is the mathematical modeling of the control algorithm of an electronic converter. The next stage is the model to be implemented in a simulation environment in order to study and set up a real technological process based on comparison with real and numerically simulated data. The input parameters for this modeling are divided into the following categories:

- Main materials of the brazed joint-copper, brass, stainless steel.

- Tabular data on the change in the resistance of joints composed of the three types of material, obtained by numerical 3D simulation of the heating process (graphically represented in Figure 1), with the geometry presented in Figure 2 and pipe dimensions $6 \times 1 \mathrm{~mm}$ (outer pipe) and $4 \times 0.7 \mathrm{~mm}$ (inner pipe).

- Shape of the inductor (presented in Figure 2) corresponding to the real induction 
system in order to compare and verify the results.

- Induction technological system consisting of the following components:

- Resonant inverter-output parameters: power: $15 \mathrm{~kW} /$ current: $34 \mathrm{~A} /$ voltage: $450 \mathrm{~V} /$ operating frequency: $96 \mathrm{kHz}$.

- Heat station with gear ratio: 6:1.

- $\quad$ Brazing station with gear ratio: 4:1.

- Heating profiles-obtained using the 3D simulation model (details of the profiles in Section 4, Synthesis of Control and Demonstration).

\section{Modeling}

The task described in Section 2 was performed by modeling in the MATLAB Simulink ${ }^{\mathrm{TM}}$ environment [21]. The modules of the model are constructed according to the presented block diagram of the algorithm in Figure 6.

The basic scheme of the model is presented in Figure 7.

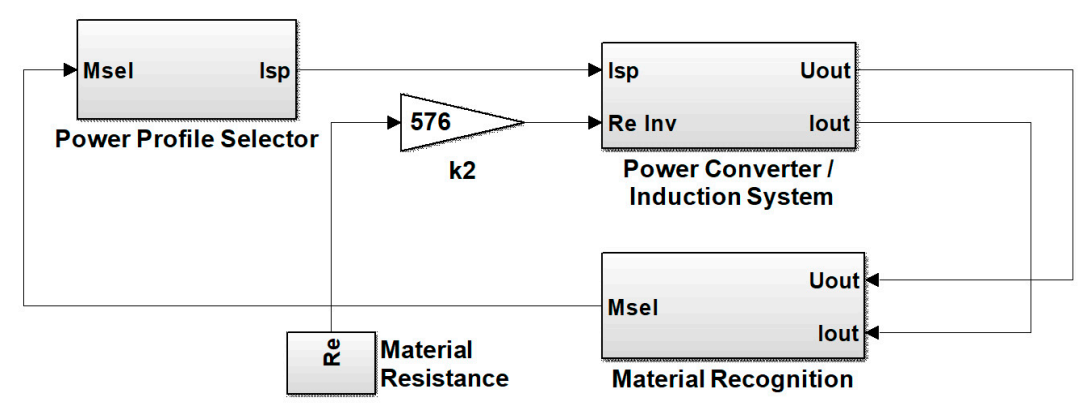

Figure 7. Basic scheme of the model.

The basic scheme consists of the following blocks with the corresponding input and output parameters:

- Power Converter/Induction System - unit including the power part of the induction system: converter, matching circuits, inductor. This is detailed in Figure 8.

- Inputs:

- $I_{s p}$-current reference.

- $R_{e \text { inv }}$-reduced equivalent resistance to the inverter output.

- Outputs:

- $U_{o u t}$-output voltage of the inverter.

- $I_{\text {out }}$-inverter output current.

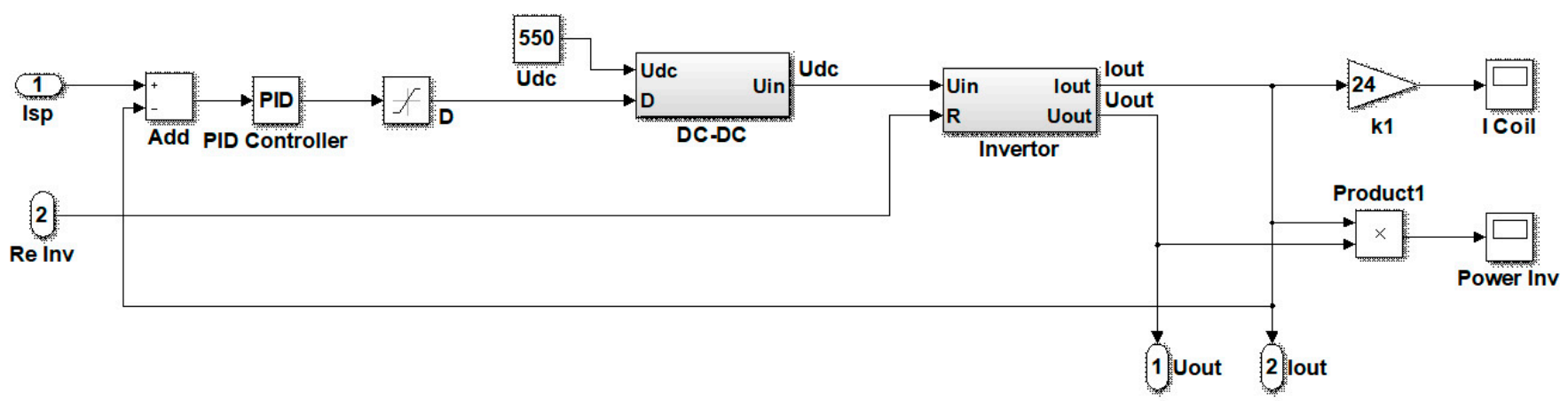

Figure 8. Controller, DC/DC converter, and induction system.

The module is a system consisting of a PID controller, a DC/DC converter powered by DC voltage, and a resonant inverter module. The block $k 1$ represents the total conversion factor of the induction and brazing station (in the specific example $6 \times 4=24$ ). The 
output indicators are Icoil—current through the inductor and Power inv—output power of the inverter.

In this case, the inverter uses a power circuit of a bridge resonant inverter with reverse diodes. Figure 9 shows a simplified circuit of an inverter implemented with $\mathrm{N}$-channel MOSFET transistors.

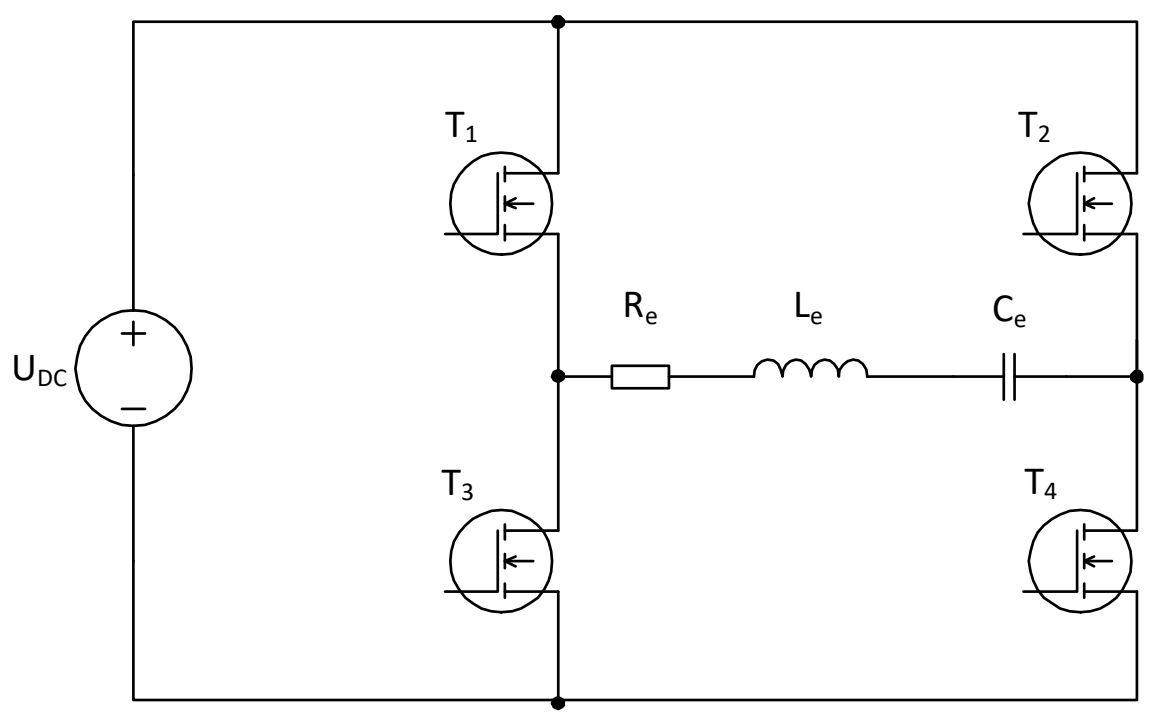

Figure 9. Inverter model with equivalent load.

Inverter modelling uses the switching function method. Analytical expressions describing the operation of the inverter are presented in Equation (1).

$$
\mid \begin{gathered}
i R+u+L \frac{d i}{d t}=U_{m} \cdot \operatorname{switch}(t) \\
C \frac{d u}{d t}=i
\end{gathered}
$$

where:

$R, L$ and $\mathrm{C}$ are transferred to the inverter load loop;

$u$ and $i$ are the status variables;

$\mathrm{d}$ switch $(t)=\left\{\begin{array}{c}1, \text { for odd half period } \\ -1, \text { for even half period }\end{array}\right.$

- Material recognition-block responsible for the recognition of the brazed material based on its equivalent resistance (Figure 10). The identification of the brazing material is performed on the basis of a test with a predetermined value of current, applied for a duration of $1 \mathrm{~s}$.

- Inputs:

- $\quad U_{\text {out }}$-output voltage of the inverter.

- $I_{\text {out }}$-inverter output current.

$\circ \quad$ Outputs:

- $M_{s e l}$-index of the selected material.

The module consists of an input part for determining the average resistance of the material during the test period, a panel with reference values obtained during the training of the system and a function for selecting a heating profile. 


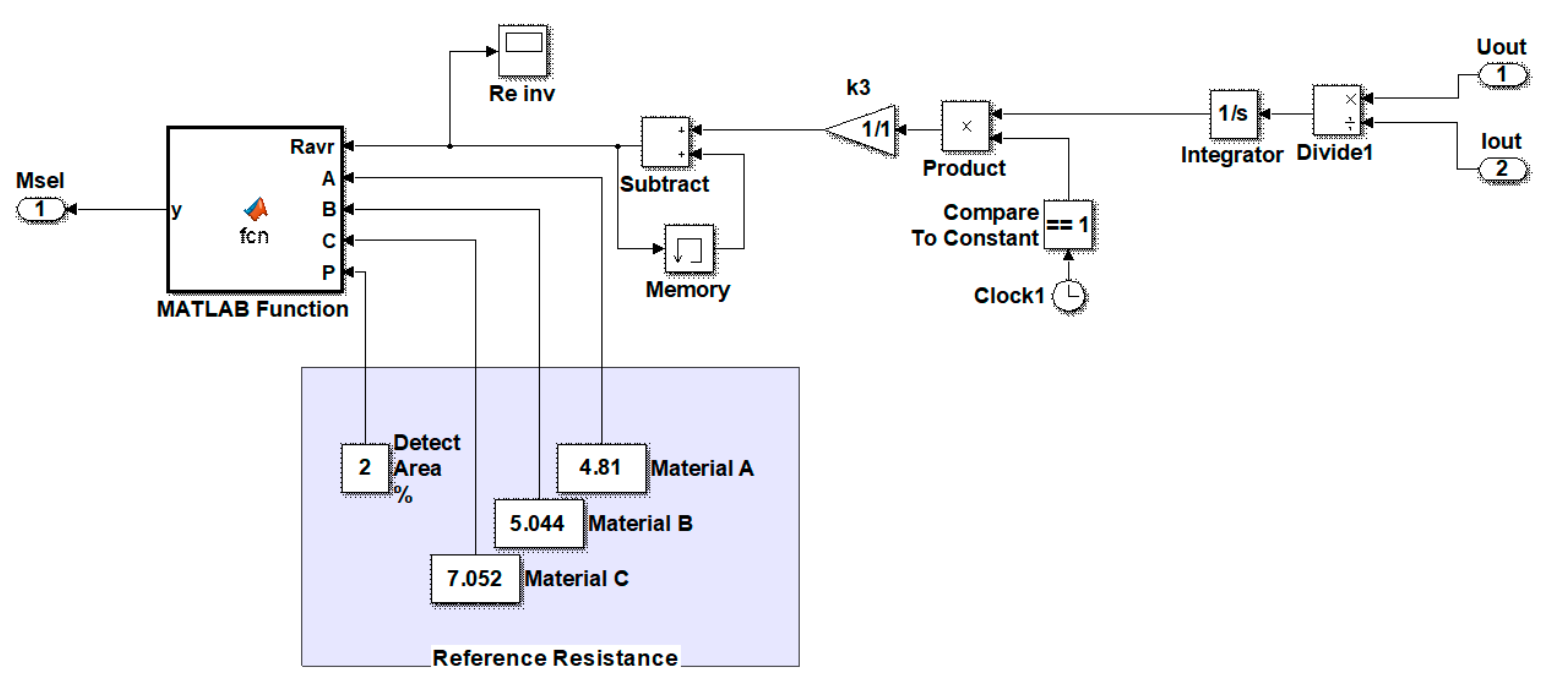

Figure 10. Material recognition.

The input part for determining the average resistance of the material during the test period ( $1 \mathrm{~s}$ ) is the structure that supplies the input signal to $R_{a v r}$. The analytical expression for the calculation is presented in Equation (2).

$$
R_{\text {avr }}=\frac{1}{T} \int_{0}^{T} \frac{U_{\text {out }}(t)}{I_{\text {out }}(t)} d t \text { for } \frac{U_{\text {out }}}{I_{\text {out }}} \geq 0 \text { and } T=1
$$

The algorithm for working with this module is discussed in more detail in Section 4.

- $\quad$ Power Profile Selector-module switching the operating modes of the system (Figure 11):

- Inputs:

- $M_{\text {sel }}$-index of the recognized material.

- Outputs:

- $I_{s p}$-current reference to the induction converter.

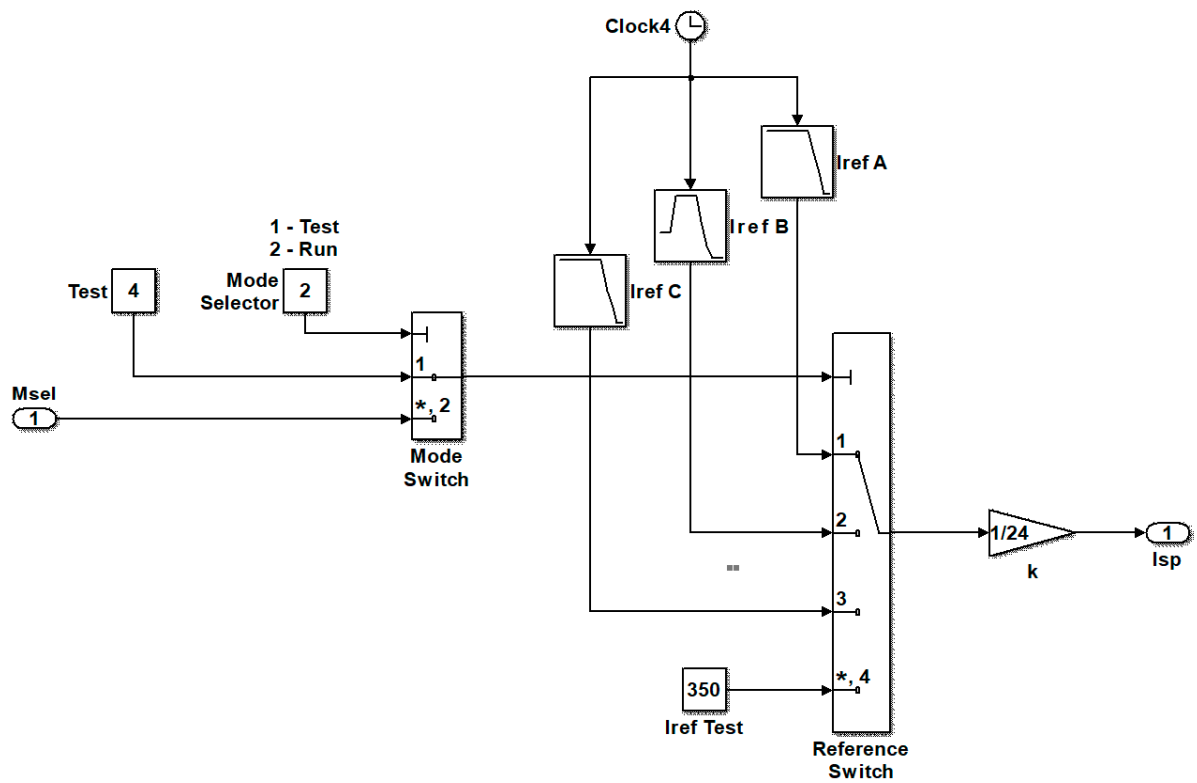

Figure 11. Control of the operating mode and profiles. 
For the purposes of the simulation, a module with resistance values of the three different materials with which the study was conducted was compiled (Reference ResistanceFigure 12). Resistance reference values were obtained using numerical 3D modeling. The values are presented in Figure 1.

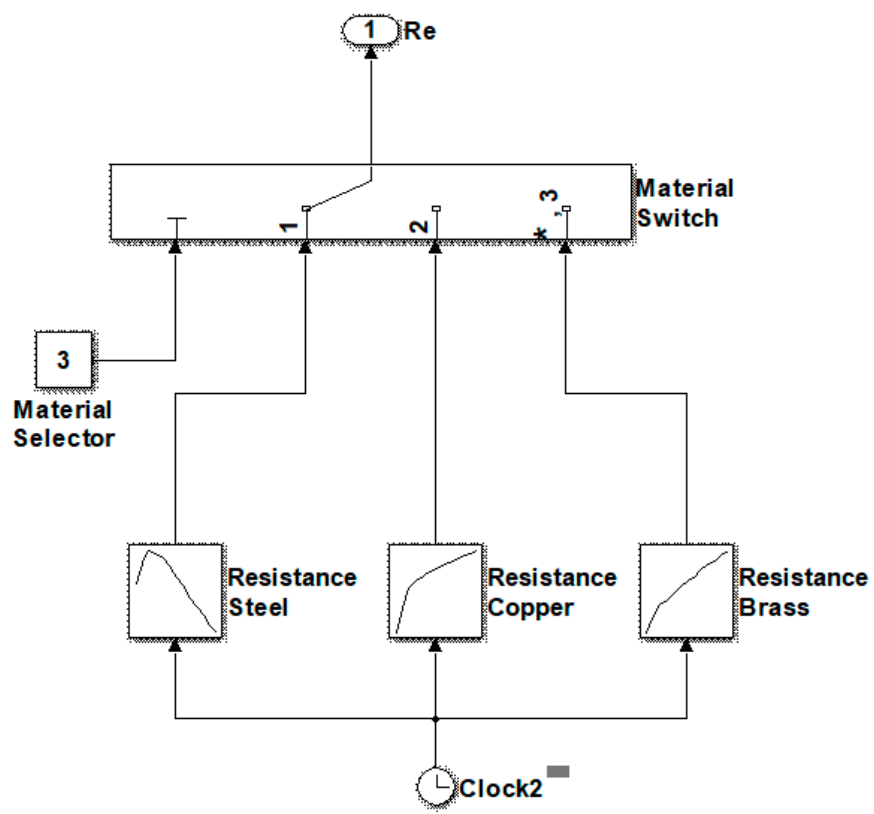

Figure 12. Setting of the equivalent resistance of materials.

\section{Synthesis of Control and Demonstration}

The control algorithm is mainly divided into two parts-system training, based on a test procedure for material recognition, and process execution in accordance with the already-stored parameters during the training.

Training is essentially the process of setting up the system to work with the various materials that are brazed in a particular batch. It is conducted once-at the beginningfor the whole batch. Due to its specifics, it is performed by the shift manager or other responsible employee of the company's staff.

The demonstration of the work with the algorithm is performed in the following sequence:

- $\quad$ Set the Mode Selector of the Power Profile Selector module to Test mode (1).

- Set the Material Selector of the Reference Resistance module to position 1. In our case, this is the table with the resistance of a joint made of stainless steel pipes.

- Start the process in which the induction system works with the pre-selected test current Iref test. The value selected in the current study was 350 A, corresponding to the operating current of the material with the highest resistance (stainless steel). This value can be set by the user depending on the specific needs and application of the system.

- After the end of the test process, the system calculates the value of the resistance from the indicator Ravr inv/formula Equation (2)

- $\quad$ Record the obtained value in one of the cells of the panel for reference values (in our case, Material A).

- Repeat the above steps with the other materials, selecting them with Material Selectorposition 2 for copper pipes and position 3 for brass pipes. Record the values obtained in the Material B and Material C cells

The values obtained from our training simulation are presented in Table 1. 
Table 1. Training of the material recognition system.

\begin{tabular}{cccccc}
\hline & Ravr Inv & Low & High & Delta & Interval \\
\hline Material A $(\Omega)$ & 4.81 & 4.7138 & 4.9062 & 0.1924 & \\
\hline Material B $(\Omega)$ & 5.044 & 4.94312 & 5.14488 & 0.20176 & -0.03692 \\
\hline Material C $(\Omega)$ & 7.052 & 6.91096 & 7.19304 & 0.28208 & -1.76608 \\
\hline Detect Area $(\%)$ & 2 & & & & \\
\hline
\end{tabular}

An interesting parameter here is Detect Area, which sets the interval in which the measured value of resistance must fall in order to successfully recognize the material of the assembly. This is the delta value, representing the difference between High and Low. From a practical point of view, it is better for this interval to be wider in order to be able to cover a larger range of tolerances during operation (displacement of the assembly, positioning of the inductor, etc.). On the other hand, depending on the combination of materials being trained, a limitation of this interval is obtained in order to avoid overlapping of the recognition intervals. An indicator of the status of the intervals is the value in the Interval column - if it is negative, there is no overlap.

The second step in training the system is setting appropriate values to perform the heating process depending on the assembly materials used. There are two possibilities (Figure 13):

- Constant current during the whole process (Figure 13a) - this is the case when it can be assumed that the heating process is uncontrolled, as the system will work with a constant (unchanging) in time reference to the controller.

- Dynamic current profile (Figure 13b) - the setpoint to the induction system controller changes over time in order to achieve an optimal temperature process.

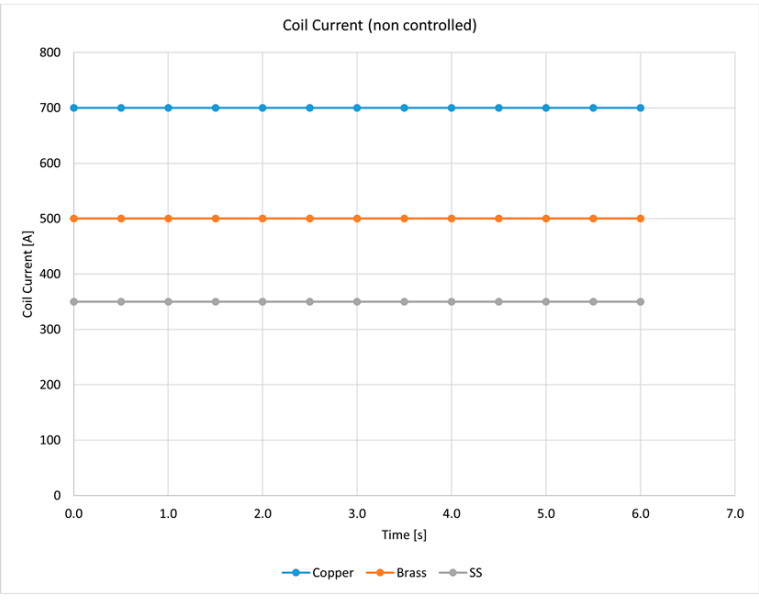

(a)

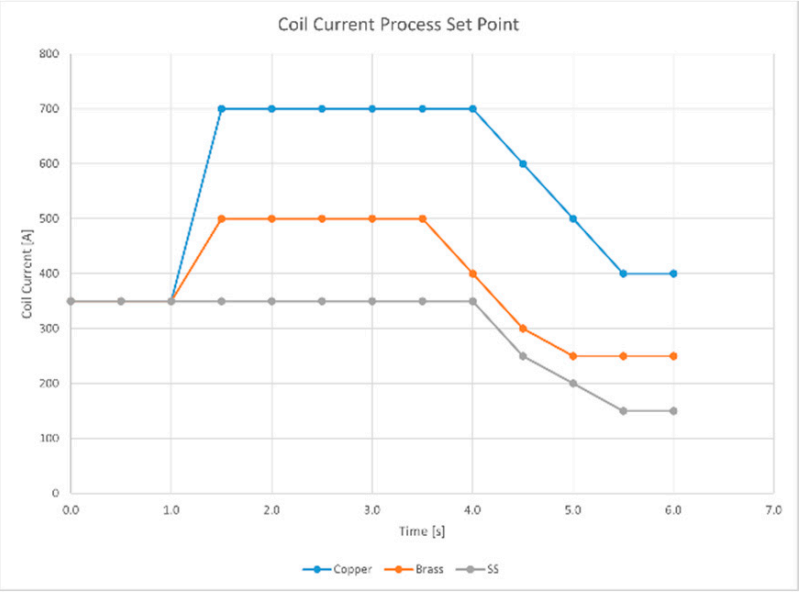

(b)

Figure 13. Possible reference current profiles: (a) constant current; (b) dynamic current profile.

The current profile in this case is obtained by selecting the values for each of the materials and verifying them through a pre-created 3D model. As a result of the use of a controlled current profile through the inductor, the results of the heating of the various materials are as presented in Figure 14.

The selected profiles correspond to the technological process of brazing. While they can be further refined during tests in real conditions, they present a good starting point for improving the performance in industrial practice. By entering the selected profiles in the Power Profile Selector module in the respective cells Iref A, Iref B and Iref C, it is assumed that the process of training the system is completed. 


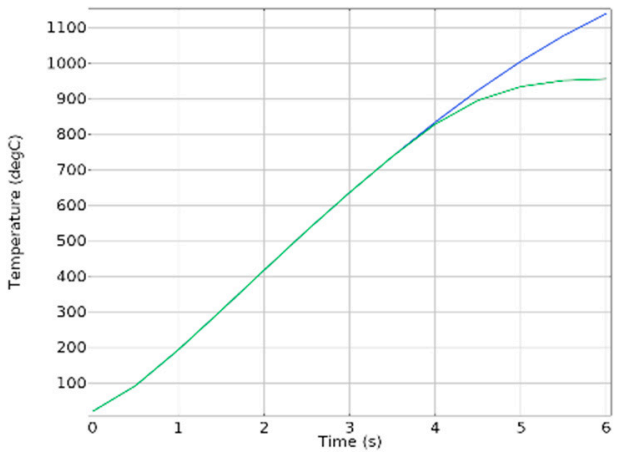

(a)

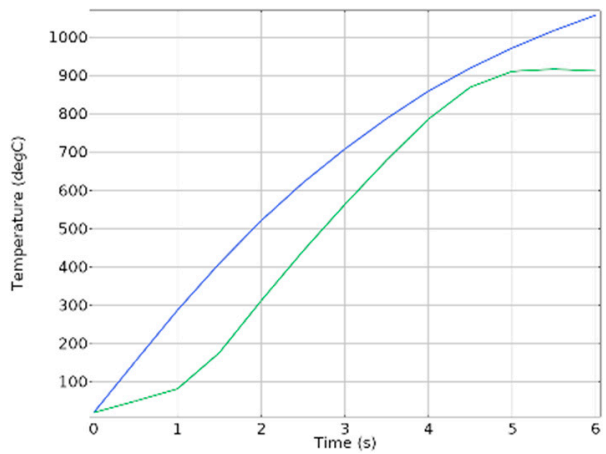

(b)

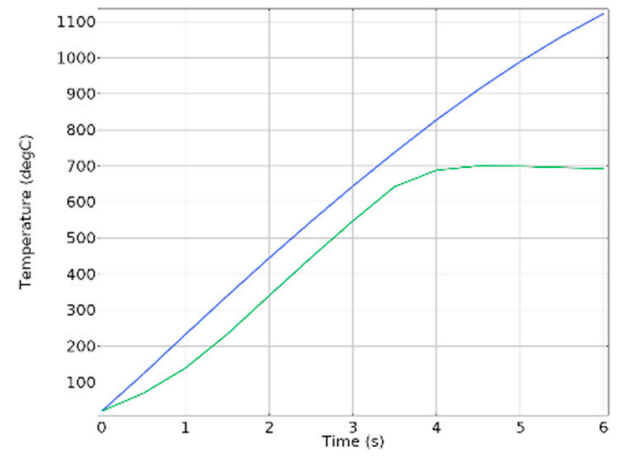

(c)

Figure 14. Comparison of the heating of the assemblies: (a) stainless steel, (b) copper, (c) brass; blue-constant current; green-dynamic current profile.

Execution is the process of brazing the various parts (materials) of the batch. Execution is performed for each detail of the batch, and this is conducted by the operator. The operator does not have to set up the system but merely needs to input the details correctly, because after the training, the type of assembly is automatically recognized, and a suitable control of the inverter output current to achieve the required quality is generated.

Demonstration of the operation of the already-trained system process is performed following the steps below:

- $\quad$ Put the Mode Selector on the Power Profile Selector module in Run mode (2).

- Select one of the materials for simulation using the Material Selector of the Reference Resistance module.

- Start the process simulation, and the trained system takes into account the readings of $U_{\text {out }}$ and $I_{\text {out }}$ of the induction system (Figure 8 )

- The system checks whether the $R_{a v r}$ average resistance corresponds to the material we selected. 
Verifying the correct operation of the system- if we perform the above steps for each of the materials by changing the value of Material Selector $(1,2$, or 3$)$, the system itself generates the correct set of the control. This process corresponds to the brazing of various parts (materials) by the operator. The following figures show the results of the verification of the algorithm in the mode of automatic recognition and execution of the specified profile:

- Material Selector position 1-Figure 15. In comparison with the reference profile of Figure 13b, this figure shows that the profile worked out by the system corresponds to the stainless steel assembly.

- Material Selector position 2-Figure 16. We compare in the same way and see that it corresponds to the copper assembly.

- Material Selector position 3-Figure 17. The profile corresponds to the brass assembly.
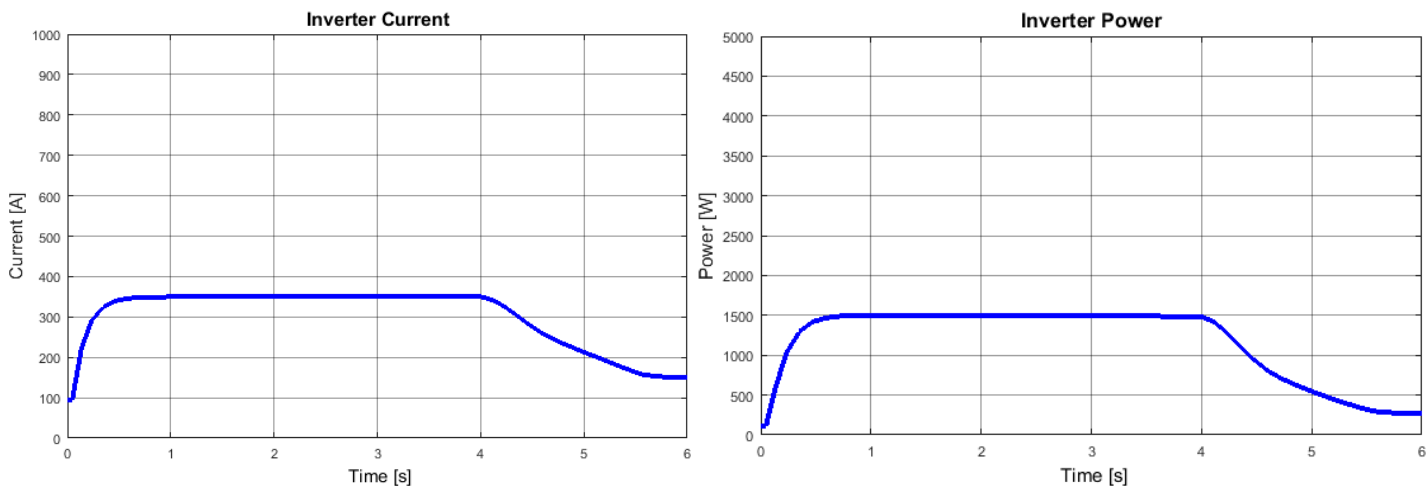

Figure 15. Material Selector (1).
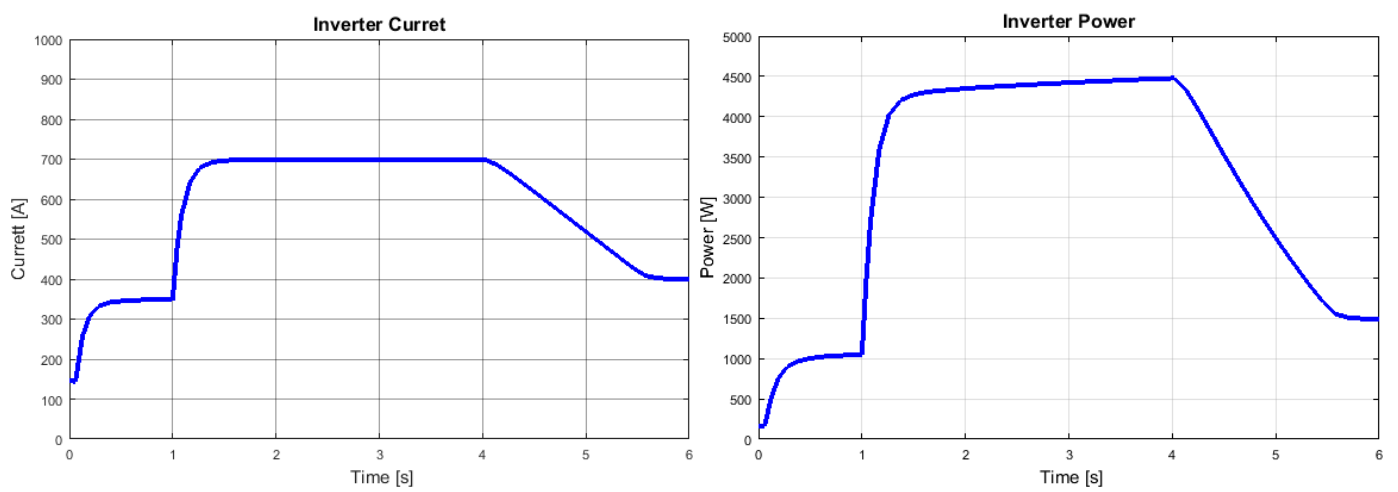

Figure 16. Material Selector (2).
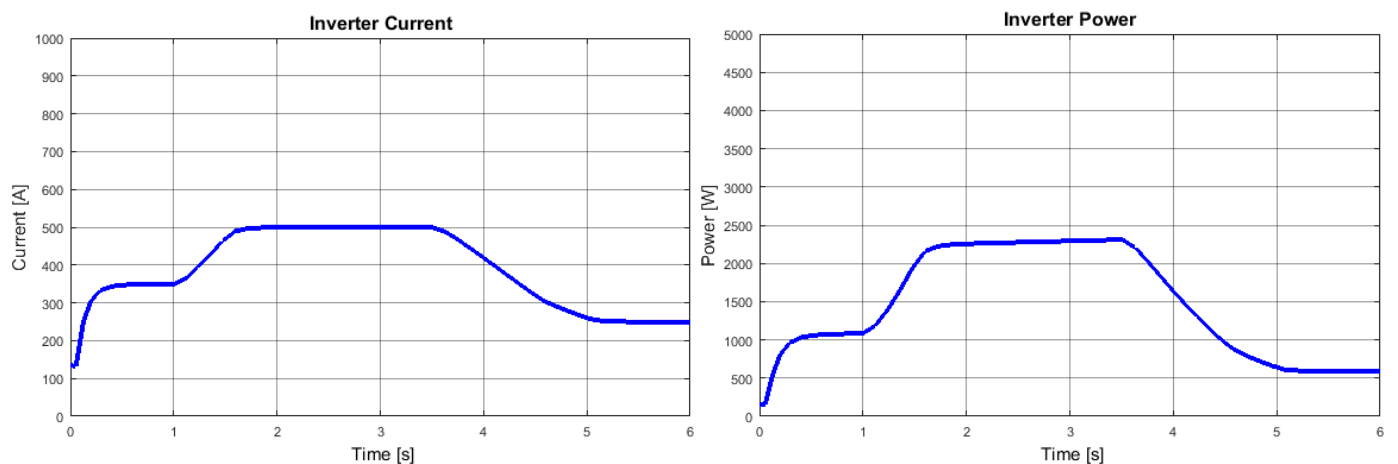

Figure 17. Material Selector (3). 
In the same way, we can compare the output power of the inverter with that of Figure 3. Correct recognition and compliance are also reported, according to the selected modes.

In all figures, the period of $1 \mathrm{~s}$ at the beginning of the process provided for the recognition of the assembly material is visible.

\section{Conclusions and Guidelines for Future Work}

This paper presents a synthesis of control of an electro-technological system for induction brazing, using artificial intelligence techniques. In this way, it is possible to perform different types of assemblies with one system, as the adjustment is performed by the test procedure once and on the basis of modeling the materials that are used in production. This is useful when working with different types of materials and when a change in the setting of the control system is required to ensure the quality of the joints. On the other hand, the use of artificial intelligence elements makes it possible to work with electronic technology systems and lower-skilled personnel. This is important in view of the growing shortage of workers in the industry.

Guidelines for future work can be summarized in two steps:

- Implementation of the described algorithm in a real induction brazing system, using modern microprocessor-based units for control.

- Implementation of a function for automatic generation of heating profiles through a real test process performed by an experienced technologist in industrial conditions. This will allow easy achievement of the desired technological results without the need for a complex and detailed design of the temperature profile.

The results presented in this paper show the possibility for successful implementation of process control. This would allow the wider use of induction brazing in industry and its preference over classical methods.

On the other hand, the use of modern control techniques, such as model predictive control, fuzzy logic, and neural networks, provides additional opportunities to improve the quality of production from the technological process and to ensure the performance of power electronic systems.

Author Contributions: D.G., B.G., and N.H. were involved in the full process of producing this paper, including conceptualization, methodology, modeling, validation, visualization, and preparing the manuscript. All authors have read and agreed to the published version of the manuscript.

Funding: This research was funded by the European Regional Development Fund within the Operational Program "Science and Education for Smart Growth 2014-2020" under the Project CoE "National Center of Mechatronics and Clean Technologies BG05M2OP001-1.001-0008".

Conflicts of Interest: The authors declare no conflict of interest.

\section{References}

1. Rudnev, V.; Loveless, D.; Cook, R.L. Handbook of Induction Heating, 2nd ed.; CRC Press: Boca Raton, FL, USA, 2017; ISBN1 978-11387-4874-3. ISBN2 1138748749. ISBN3 978-1-4665-5395-8.

2. Zinn, S.; Semiatin, S.L. Elements of Induction Heating: Design Control and Applications; ASM International: Almere, The Netherlands, 1988; ISBN1 0871703084. ISBN2 9780871703088.

3. Johnson, I.A. 20 Induction Cooking and Heating. In Wireless Power Transfer, 2nd ed.; River Publishers: Aalborg, Denmark, 2016; pp. 681-702.

4. Davies, J. Conduction and Induction Heating; IEE Power Engineering Series 11; On behalf of the Institution of Electrical Engineers; P. Peregrinus Ltd.: London, UK, 1990; ISBN1 0-86341-174-6. ISBN2 978-0-86341-174-8.

5. Lupi, S.; Forzan, M.; Aliferov, A. Induction and Direct Resistance Heating: Theory and Numerical Modeling; Springer International Publishing: Cham, Switzerland, 2015; ISBN1 978-3-319-03478-2. ISBN2 978-3-319-03479-9.

6. Danilushkin, A.; Bazarov, A.; Zhivotyagin, D. Synthesis of Algorithms and Optimal Control System of Start-Up Modes of Continuous Induction Installation. In Proceedings of the 2020 International Conference on Industrial Engineering, Applications and Manufacturing (ICIEAM), Sochi, Russia, 18 May 2020; pp. 1-5. [CrossRef]

7. Weis, S.; Fedorov, V.; Elssner, M.; Uhlig, T.; Hausner, S.; Wagner, G.; Wielage, B. Research trends in brazing and soldering. Weld. Technol. Rev. 2017, 89. [CrossRef] 
8. Fabian, R. Vacuum Technology: Practical Heat Treating and Brazing; ASM International: Almere, The Netherlands, 1993; ISBN1 0-87170-477-3. ISBN2 9781615031511. ISBN3 1615031510. ISBN4 9780871704771.

9. Filatova, D.; Grzywaczewski, M. Optimal Control of Induction Heating: Theory and Application. In Modeling, Design, and Simulation of Systems with Uncertainties; J.B. Metzler: Stuttgart, Germany, 2011; pp. 153-173.

10. Rapoport, E.; Pleshivtseva, Y. Optimal Control of Induction Heating Processes; Dekker Mechanical Engineering; CRC/Taylor \& Francis: Boca Raton, FL, USA, 2007; ISBN1 0849337542. ISBN2 9780849337543.

11. Grozdanov, D.; Tarnev, K.; Hinov, N. Electromagnetic Modeling and Thermal Analysis of a Non-Axisymmetric System for Induction Brazing. Energies 2020, 13, 3656. [CrossRef]

12. Ge, Y.; Hu, R.; Zhang, Z.; Shen, Q. Optimization Control of Induction hardening. Process. Proc. Int. Conf. Mech. Autom. IEEE 2006, 1126-1130. [CrossRef]

13. Roberts, P. Introduction to Brazing Technology. In Introduction to Brazing Technology; Apple Academic Press: Cambridge, MA, USA, 2016; p. 978.

14. Zhao, S.; Blaabjerg, F; Wang, H. An Overview of Artificial Intelligence Applications for Power Electronics. IEEE Trans. Power Electron. 2021, 36, 4633-4658. [CrossRef]

15. UltraFlex Power Technologies. Available online: https://ultraflexpower.com/ (accessed on 21 March 2021).

16. Zerouali, S.; Allag, A.; Mimoune, S.M.; Hamida, A.H.; Khanniche, S.; Feliachi, M. An Adaptive Control Applied to Series Resonant Inverter for Induction Heating. Proc. Int. Univ. Power Eng. Conf. IEEE 2006, 2, 633-636.

17. Chaboudez, C.; Clain, S.; Glardon, R.; Mari, D.; Rappaz, J.; Swierkosz, M. Numerical modeling in induction heating for axisymmetric geometries. IEEE Trans. Magn. 1997, 33, 739-745. [CrossRef]

18. Leitner, M.; Aigner, R.; Grün, F. Numerical Fatigue Analysis of Induction-Hardened and Mechanically Post-Treated Steel Components. Machines 2019, 7, 1. [CrossRef]

19. Panek, D.; Karban, P.; Dolezel, I. Calibration of Numerical Model of Magnetic Induction Brazing. IEEE Trans. Magn. 2019, 55, 1-4. [CrossRef]

20. Khazaal, M.H.; Abdulbaqi, I.M.; Thejel, R.H. Modeling, design and analysis of an induction heating coil for brazing process using FEM. In Proceedings of the 2016 Al-Sadeq International Conference on Multidisciplinary in IT and Communication Science and Applications (AIC-MITCSA), Baghdad, Iraq, 9 May 2016; pp. 1-6.

21. The MathWorks, Inc. Available online: www.mathworks.com (accessed on 1 February 2021). 